\title{
Studies of the Sensitivity Dependence of Float Zone Silicon Diodes on Gamma Absorbed Dose
}

\author{
K. C. S. Pascoalino ${ }^{1}$ \\ Centro de Tecnologia das Radiações CTR, Instituto de Pesquisas Energéticas e Nucleares IPEN/CNEN \\ Caixa Postal 11049, São Paulo-SP 05422-970, Brazil \\ E-mail: kellypascoalino@yahoo.com.br
}

\section{T. C. dos Santos}

Centro de Tecnologia das Radiações CTR, Instituto de Pesquisas Energéticas e Nucleares IPEN/CNEN Caixa Postal 11049, São Paulo-SP 05422-970, Brazil

E-mail: thais_cavalherieyahoo.com.br

\section{R. F. Barbosa}

Centro de Tecnologia das Radiações CTR, Instituto de Pesquisas Energéticas e Nucleares IPEN/CNEN Caixa Postal 11049, São Paulo-SP 05422-970, Brazil

E-mail: profcelta@hotmail.com

\section{F. de Camargo}

Centro de Tecnologia das Radiações CTR, Instituto de Pesquisas Energéticas e Nucleares IPEN/CNEN Caixa Postal 11049, São Paulo-SP 05422-970, Brazil

E-mail: fcamargo@ipen.br

\section{J. A. C. Gonçalves}

Centro de Tecnologia das Radiações CTR, Instituto de Pesquisas Energéticas e Nucleares IPEN/CNEN Caixa Postal 11049, São Paulo-SP 05422-970, Brazil

Departamento de Física, Pontifícia Universidade Católica de São Paulo

Rua Marquês de Paranaguá 111, São Paulo-SP 01303-050, Brazil

E-mail: josemaryeipen.br

\section{C. Bueno}

Centro de Tecnologia das Radiações CTR, Instituto de Pesquisas Energéticas e Nucleares IPEN/CNEN Caixa Postal 11049, São Paulo-SP 05422-970, Brazil

Departamento de Física, Pontifícia Universidade Católica de São Paulo

Rua Marquês de Paranaguá 111, São Paulo-SP 01303-050, Brazil

E-mail: ccbueno@ipen.br 
In this work it is presented the dosimetric results obtained with a batch of nine junction silicon diodes, developed in the framework of CERN RD50 Collaboration, as on-line gamma dosimeters. The samples irradiation was performed using a ${ }^{60} \mathrm{Co}$ irradiator (Gammacell 220) which delivers a dose-rate of $2 \mathrm{kGy} / \mathrm{h}$. The diodes were irradiated with different doses from 5 kGy up to $50 \mathrm{kGy}$.

Keywords: Rad-hard silicon diodes, gamma dosimetry.

XXXIV edition of the Brazilian Workshop on Nuclear Physics,

Foz de Iguaçu, Parana state, Brasil

5-10 June 2011 


\section{Introduction}

Several advantages of silicon diodes which include small size, low cost, high sensitivity and wide availability, make them suitable for dosimetry and for radiation field mapping [1]. However, the small radiation tolerance of ordinary silicon devices has imposed constraints on their application in intense radiation fields such as found in industrial radiation processes. This scenario has been changed with the development of radiation hard silicon devices to be used as track detectors in high-energy physics (HEP) experiments. Currently, the most used devices in HEP are grown by the float zone (FZ) technique, due to their high purity and resistivity [2-3].

These results associated with previous results obtained in our research group with rad-hard Si diodes $[1,4]$ have encouraged us to evaluate the stability of FZ silicon diodes response as online gamma dosimeter.

\section{Materials and methods}

The $\mathrm{n}$ type FZ diodes used in this work, with active area of $25 \mathrm{~mm}^{2}$, were processed by the Microelectronics Center of Helsinki University of Technology on Si wafer of $300 \mu \mathrm{m}$ thickness and resistivity of $10 \mathrm{k} \Omega . \mathrm{cm}$. The nine samples were irradiated at CTR-IPEN-CNEN/SP with gamma rays from a ${ }^{60} \mathrm{Co}$ source (Gammacell 220 - Nordion) in order to each diode received different doses from $5 \mathrm{kGy}$ up to $50 \mathrm{kGy}(5,10,15,20,25,30,35,40$ and $50 \mathrm{kGy})$.

During the irradiation, the unbiased diodes were connected through a low-noise coaxial cable to the input of a KEITHLEY ${ }^{\circledR} 617$ electrometer, in order to monitor the devices photocurrent as a function of the exposure time. The devices were enclosed in a black PMMA chamber to provide protection from mechanical stress and light.

\section{Results}

The current values obtained during the samples irradiation are presented in Figure 1. The currents decreased about $3 \%$ and $19 \%$ for samples that absorbed $5 \mathrm{kGy}$ and $50 \mathrm{kGy}$, respectively. This drop was expected since the sensitivity of the diodes falls with the radiation dose [5].

All the samples exhibited the same current response behaviour; however, the values are slightly different. This difference can be observed from the Figure 2 that shows an enlargement of the graph shown in Figure 1 for absorbed doses up to $5 \mathrm{kGy}$. The maximum difference between the current values obtained during the irradiation steps in this interval was about $3 \%$.

The dosimetric parameter utilized to study the response of these devices was the charge (obtained through the integration of the current signals) as a function of the exposure time. The dose-response curve of this batch of diodes is shown in the Figure 3. 


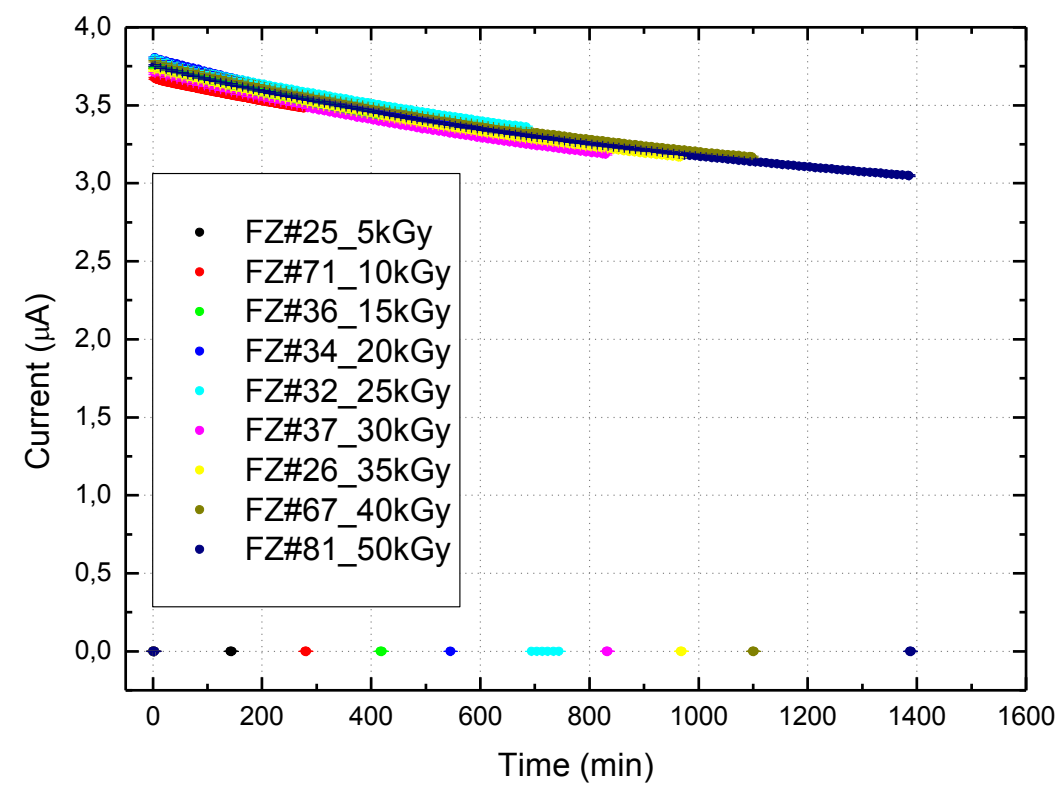

FIGURE 1. Current values obtained during the irradiation steps as a function of exposure time to each sample.

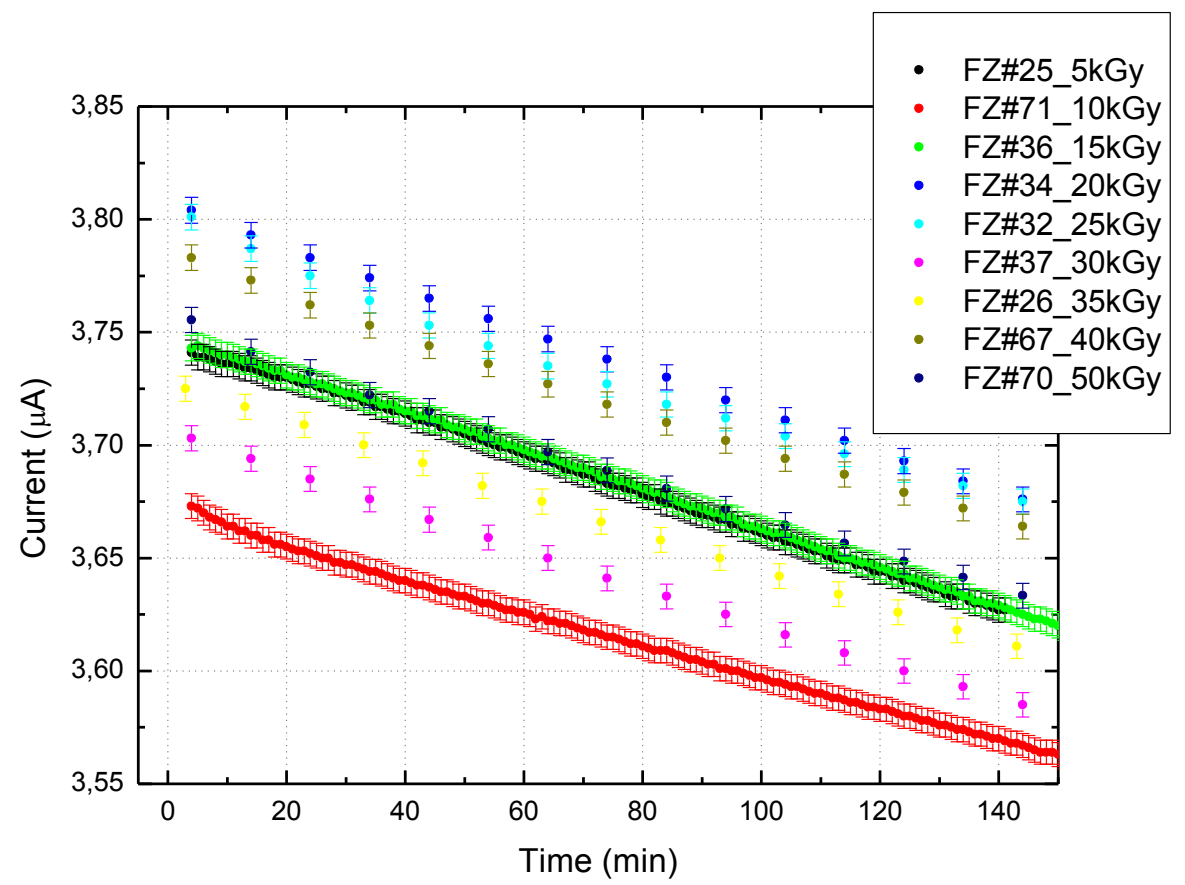

FIGURE 2. Current values obtained during the irradiation steps as a function of exposure time to each sample up to $5 \mathrm{kGy}$ of absorbed dose. 


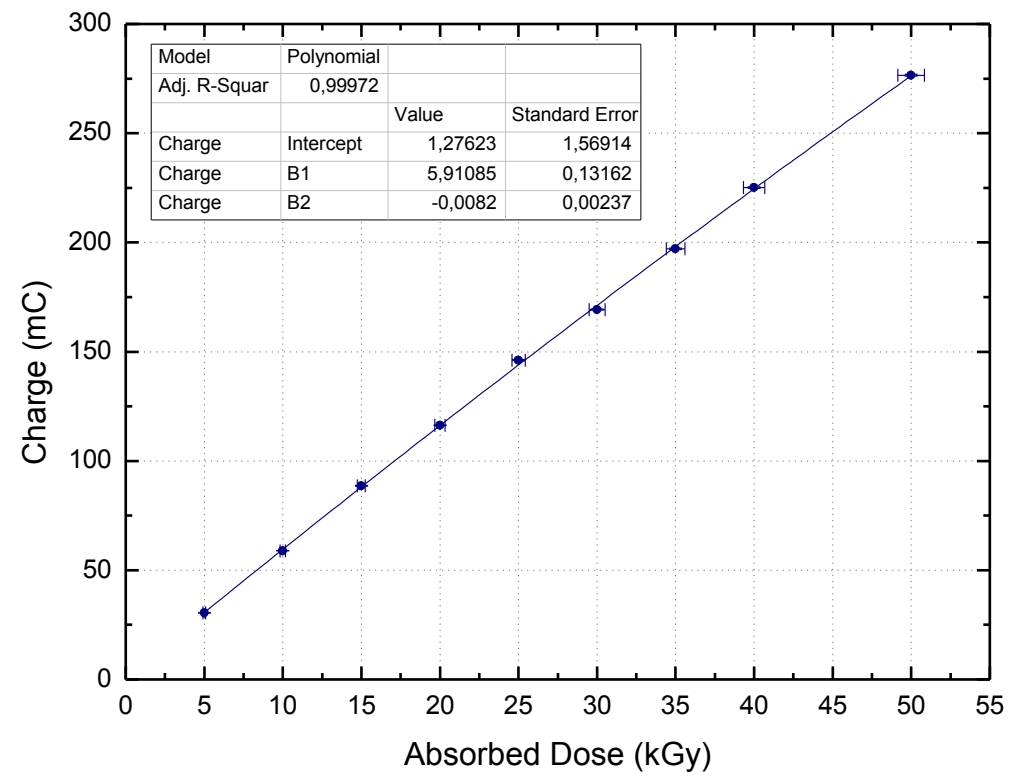

FIGURE 3. Dose-response curve obtained by the integration of the current signals of each sample.

According to Figure 3, a second order polynomial was fitted to dose-response curve.

In order to evaluate the reproducibility of the devices, we have compared the charge generated in the samples for an absorbed dose about $5 \mathrm{kGy}$. The results are presented in Figure 4.

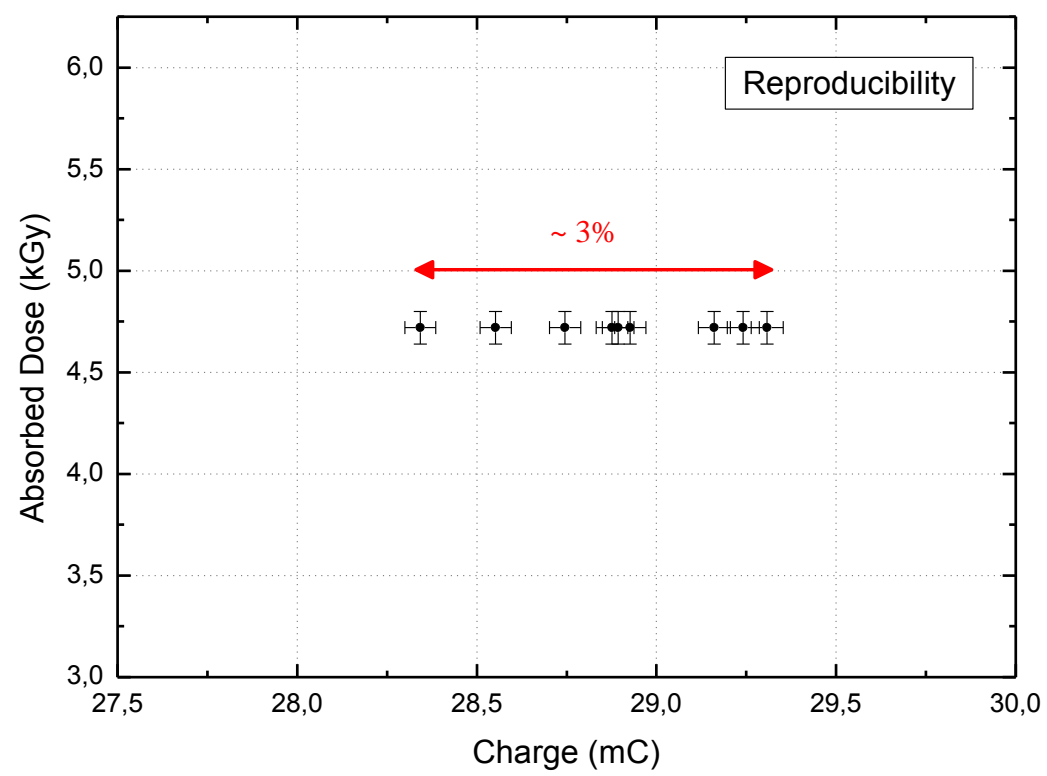

FIGURE 4. Charge generated in the samples during the irradiation steps up to $5 \mathrm{kGy}$ of absorbed dose.

The maximum variation of the charge was about $3 \%$. It is important to note that these results are better than those obtained with routine polimetylmetacrilate (PMMA) dosimeters used in radiation processing dosimetry [6]. 


\section{Conclusions}

The results obtained show that the dosimetric response of FZ devices for the batch analyzed presents a small and acceptable variation. In addition, the good result from reproducibility study indicates that these devices can be used as on-line dosimeter in gamma radiation processing.

Complementary dosimetric characteristics of the FZ diodes still remains under study in our research group.

\section{Acknowledgments}

The collaboration of Eng. Elizabeth S. R. Somessari and Eng. Carlos Gaia da Silveira from Gammacell 220 and Panoramic staff is highly acknowledged. K. C. S. Pascoalino is grateful to CAPES for the award of scholarships. This work was partially supported by Conselho Nacional de Desenvolvimento Científico e Tecnológico (CNPq) under contract $\mathrm{n}^{\circ}$ 310493/2009-9.

\section{References}

[1] F. Camargo, J. A. C. Gonçalves, H. J. Khoury, C. M. Napolitano, J. Härkönen and C. C. Bueno, $M C z$ diode response as a high-dose gamma radiation dosimeter, Radiat. Meas. 43 (2008) 1160.

[2] A. G. Bates and M. Moll, A comparison between irradiated magnetic Czochralski and float zone silicon detectors using the transient current technique, Nucl. Instrum. Meth. A 555 (2005) 113.

[3] G. Casse, Overview of the recent activities of the RD50 collaboration on radiation hardening of semiconductor detectors for the sLHC, Nucl. Instrum. Meth. A 598 (2009) 54.

[4] T. C. dos Santos, W. F. P. Neves-Junior, J. A. C. Gonçalves, C. M. K. Haddad, C.C. Bueno, Evaluation of rad-hard epitaxial silicon diode in radiotherapy electron beam dosimetry, Radiat. Meas. in press (2011).

[5] G. Rikner and E. Grusell, General specifications for silicon semiconductors for use in radiation dosimetry, Phys. Med. Biol. 32 (1987) 1109.

[6] ISO/ASTM 51276, 2002, G Standard practice for use of a polymethylmethacrylate dosimetry system 09 . 